\title{
Modelos de Cinco Barras e de Uma Barra para Geração de Tensões Térmicas na ZF, ZAC e MB durante Soldagem a Arco
}

(Five Bars and One Bar Models for Thermal Stress Generation in the FZ, HAZ and BM during Arc Welding)

\author{
Américo Scotti ${ }^{1}$ \\ ${ }^{1}$ Universidade Federal do Paraná, Departamento de Engenharia Mecânica, Curitiba, PR, Brasil \\ scotti@ufpr.br; pesquisascotti@gmail.com
}

\begin{abstract}
Resumo
Neste trabalho é apresentado um modelo descritivo para explanar a geração de tensões térmicas em soldagem, denominado de Modelo de 5 Barras. Tomando como base o Modelo de 3 Barras amplamente utilizado com a mesma finalidade, se reivindica que o modelo proposto seja capaz de explicar a geração das tensões também na ZAC. Essas tensões seriam progressivamente menores do que na ZF e se anulando no ponto do material em que as tensões térmicas atuantes não alcancem o limite de escoamento do material nesta região. Também mostrou ser capaz de explicar que as maiores tensões vão ser geradas na ZF e que as tensões finais na junta serão definidas pelo limite de escoamento do material do cordão e pela capacidade do material em consumir essas tensões por deformação plástica. Mas, as tensões na ZAC podem ser tão altas como as do metal de solda (ZF), desde que o material da ZAC grosseira possua limite de escoamento mais alto do que do material da ZF, passando a definir o valor da tensão térmica final gerado. Já o Modelo de 1 Barra, com a mesma abordagem, permite demonstrar que as tensões térmicas são geradas quando da ausência de empenamento angular ou sob limitada deformação plástica da peça e são sempre trativas. De forma similar, as tensões finais na junta serão definidas pelo limite de escoamento do material do cordão e pela capacidade de todo o material em absorver essas tensões por deformação plástica.
\end{abstract}

Palavras-chave: tensões e deformações; tensões térmicas; modelagem

\begin{abstract}
A descriptive mode, named Five Bar Model, is presented in this work to explicate thermal stress generation in welding. Taking as base the widely known Three Bar Model, it is claimed that the proposed model is also capable of explaining stress generation at the HAZ. This stress would be progressively smaller than in the FZ, turning null at the material point in which the thermal stress do not reach the material yielding stress. In addition, the model also showed to be able to explain that the highest stress will be generated in the FZ and that the resultant stress will be defined by the yielding stress of the bead material and by the capability of the material in consuming these stresses through plastic deformation. However, the stresses in the HAZ might be as high as in the BM, once the coarse grain region of the HAZ sustains a higher yielding stress than in the FZ, defining the final intensity of the generated stress. The One bar Model, in turn, based on the same approach, allows to demonstrate that the generated thermal stresses happen when the piece is free of angular bending or at limited plastic deformation and they are always tensile stresses. Analogy, the resultant stresses on the component are defined by the yielding stress of the weld bead material and by the capacity of the whole material in accommodate the stress through plastic deformation.
\end{abstract}

Key-words: Stress and deformation; thermal stress; modeling

\section{Introdução}

Todo processo de soldagem usa, em maior ou menor escala, calor. Como este calor é distribuído de forma desigual ao longo das partes a unir, criam-se tensões térmicas. O resultado destas tensões térmicas pode se manifestar de três formas, isoladas ou conjuntamente, a saber: como deformações; como tensões armazenadas (conhecido como tensões residuais); ou

Recebido em 24/03/2014, texto final em 07/04/2014. como falha (colapso, total ou parcial, como uma trinca propagada e estancada). Vários fatores intrínsecos à fabricação soldada como um todo (material, dimensão e forma dos componentes a ser soldados, processos e parâmetros de soldagem, métodos de restrição, etc.) definem o tipo e grau do efeito resultante das tensões térmicas. É importante mencionar que até as tensões residuais pré-existentes antes da soldagem (como devido ao dobramento da chapa) influem nesta análise. Pearce et al. [1] verificaram que as tensões residuais próximos da região soldada são governadas pelo calor de soldagem, enquanto aquelas longe da solda (no metal de base) são coerentes com a tensão pré-existente. De seus resultados, pode-se concluir de que se a soldagem é feita no lado convexo de uma barra curvada (tensões trativas), as tensões pré-existentes serão eliminas (e 
não somadas) pelas tensões trativas da operação de soldagem. Por outro lado, as tensões ao lado oporto da barra e longe da região da solda continuam compressivas devido às tensões préexistentes. Assim, trincas iniciadas na região de solda poderiam ser estancadas uma vez que alcancem a região de tensões compressivas.

No caso de união de chapas, especialmente de espessuras mais finas, normalmente acontecem deformações (apesar do volume de metal fundido em chapas finas ser menor do que em relação a chapas grossas, a auto-restrição das chapas finas é muito baixa, acontecendo deformação com maior facilidade). A Figura 1 ilustra uma situação-problema de deformação em construção soldada, mostrando a importância de se prevenir deformações em soldagem. Mas, deformação, por outro lado, é uma forma de aliviar as tensões térmicas geradas (energia gasta para deformar o material). Mas quando o material não se deforma (macroscopicamente, como distorções, ou microscopicamente, na forma de acomodações de tensões), ou as tensões ficam internamente presas (as denominadas tensões residuais) ou, se superando a resistência do material, levam ao colapso da união soldada. O colapso é evidentemente indesejável. Mas também o são as tensões residuais, pois, aliadas aos esforços externos, compromete o desempenho do componente, seja por não suportar os esforços que deveria estar sujeito, como ilustra a Figura 2, ou por propiciar formação de trincas que podem se propagar com o tempo de operação também levar ao colapso do

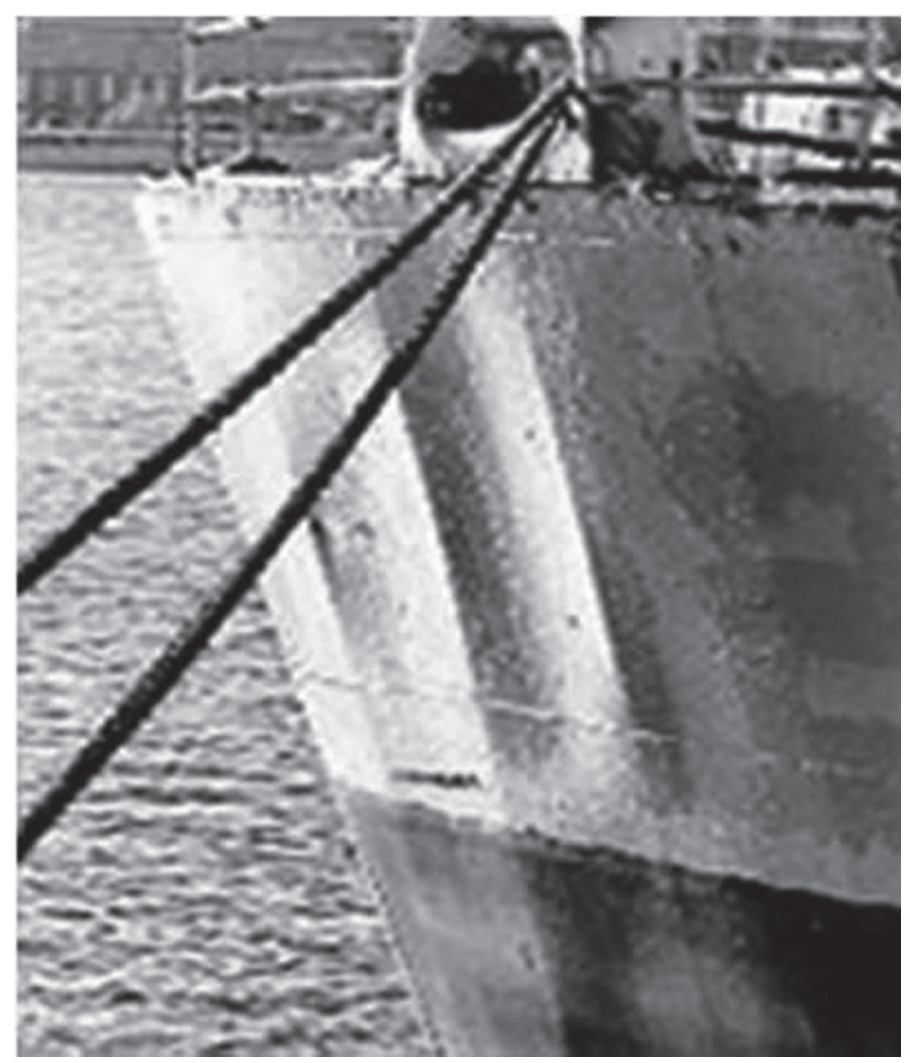

Figura 1. Ilustrações popularmente usadas para mostrar os problemas de deformações em construções soldadas: a) um costado ondulado de um navio; b) um piso metálico irregular, como acúmulo de poças de água mesmo. Por isto, componentes com tensões resíduas devem têlas aliviadas antes de colocá-los em serviço, seja por tratamento térmico de alívio de tensões (Paranhos et al. [2], por exemplo, mostram que após TTAT há uma queda acentuada no limite de escoamento e no limite de resistência do metal de solda) ou por vibração (cujos fundamentos foram estudados, por exemplo, por Yang [3]).

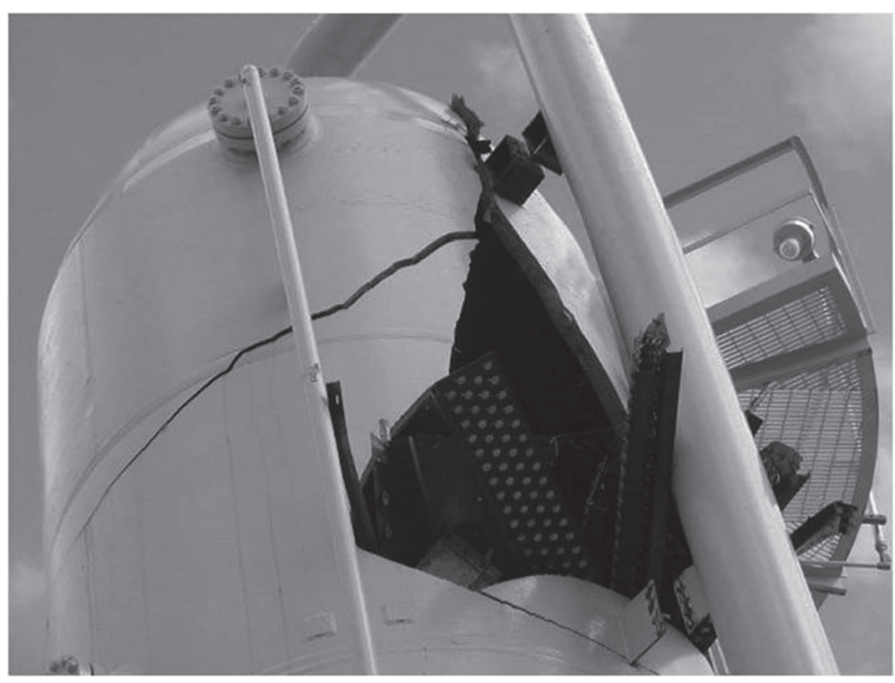

Figura 2. Ilustração de um vaso de pressão em que uma pressão acima do nominal provocou seu colapso, mesmo considerando os coeficientes de segurança de projeto, provavelmente por ter altas tensões residuais após fabricação

Existe uma série de meios para se prevenir deformações ou minimizar tensões residuais em soldagem. A tendência atual é a de se usar ferramentas numéricas-computacionais neste sentido. Mas os usuários ainda não estão convencidos da eficácia total dos métodos numéricos e a utilização dessas ferramentas no presente concentra-se no meio acadêmico ou de forma muito limitada em empresas. A razão para tal é a grande variação de propriedades físico-químicas dos materiais numa região soldada, quase impossível de serem transpostas para estes modelos ou serem preditas com precisão por eles. A modelagem da fonte de calor acoplada à peça é uma tarefa muito complexa e se torna ainda mais deficiente quando se tem geometrias complexas. Já Bachorski et al. [4] associam o pouco uso das ferramentas computacionais no meio industrial ao longo tempo de processamento computacional.

Por isto que ainda não se pode desprezar a experiência prática e suas soluções propostas. Muitas delas podendo ser usadas de forma genéricas. Outras, contudo, apresentam aspectos de controvérsias por experiências de aplicação com resultados antagônicos. Porém, acredita-se que um melhor entendimento físico dos fenômenos envolvidos seja a forma de aperfeiçoar a aplicação prática dessas soluções. E uma forma de se procurar entender o fenômeno de geração térmica em soldagem é através de modelos descritivos. Um dos mais populares é o Modelo de 3 Barras, amplamente usado na literatura acadêmica e técnica [5]. Mas só com esse modelo não se consegue explicar a transição da intensidade das tensões entre o metal de solda e o metal de base. Tampouco se consegue prever o comportamento das 
intensidades de tensões caso a propriedades mecânicas da ZAC (Zona Afetada pelo Calor) e do metal de solda sejam diferentes. Nem é possível com o Modelo de 3 Barras se explicar o perfil das tensões transversais. Desta forma, o objetivo deste trabalho é o de apresentar e discutir dois modelos, propostos pelo autor deste artigo, para descrição dos fundamentos da geração de tensões térmicas em juntas soldadas, formulados a partir do também descritivo Modelo de 3 Barras, mas que consegue um maior alcance nas definições das intensidades de tensões ao longo da seção transversal e longitudinal de uma união soldada.

\section{O tradicional Modelo de 3 Barras}

Para se entender como tensões térmicas são geradas, inicialmente precisa-se lembrar de alguns conceitos físicos. $\mathrm{O}$ primeiro exemplo disto é o uso do termo temperatura. Muitas vezes mesmo o pessoal técnico confunde temperatura com calor (quanto maior temperatura, maior calor - verdade relativa a um mesmo material e meio). Uma possível forma de entender esta diferença é a tentativa de resposta à questão sobre qual das situações o leitor preferiria para segurar firmemente por 2 minutos entre os dedos, se: a) uma chapa de $10 \mathrm{~mm}^{2}$ com 0,1 $\mathrm{mm}$ de espessura a $500^{\circ} \mathrm{C}$; b) uma chapa de $10 \mathrm{~mm}^{2}$ com $10 \mathrm{~mm}$ de espessura a $200^{\circ} \mathrm{C}$. Se o leitor não ficar atento para o fato de que a dor seria provocada pelo calor transferido para sua pele e que, devido ao menor volume, a situação "a" conserva menos calor, mesmo estando à maior temperatura, ele teria a tendência de escolher a opção "b". Um dado corpo, entretanto, apresenta maior temperatura se mais calor é introduzido nele.

Como será visto mais a frente, a razão básica para se criar tensões térmicas é a diferença de temperatura num mesmo corpo. Mas se uma parte do material está em maior temperatura do que outra, portanto contendo mais calor que o outro, acontece o fenômeno de condução de calor, medido pela propriedade de cada material denominada condutividade térmica $(k)$, cuja unidade é $\mathrm{W} /(\mathrm{m} \cdot \mathrm{K})$. É devido à condutividade térmica que o cordão de solda é resfriado continuamente, da temperatura de fusão até a temperatura ambiente. É em razão desse resfriamento, como também será visto adiante, que tensões térmicas são geradas. $\mathrm{Na}$ verdade, melhor seria falar de difusividade térmica, porque expressa quão rapidamente um corpo se ajusta por inteiro à temperatura de seu entorno (no caso, o material na vizinhança da solda). Obtém-se a difusividade $(\alpha)$ dividindo a condutividade $(k)$ pelo calor específico volumétrico $(\mu)$, .como representado pela Eq. 1.,

$\alpha=k / \mu=k / \rho c_{\rho} \cdots \quad\left[\mathrm{m}^{2} / \mathrm{s}\right]$

onde, $\rho$ é a massa específica do material $\left(\mathrm{kg} / \mathrm{m}^{3}\right)$ e $c_{p}$ a sua capacidade térmica $(\mathrm{J} /(\mathrm{g} \cdot \mathrm{K})$. Um material com $k$ pequeno conduz mal o calor da região quente para a fria, enquanto um com $\mu$ baixo demanda pouca energia térmica para aumentar a temperatura de um determinado volume dele. A difusividade é que caracteriza o volume do material que se aquecerá pelo calor difundido da solda para seu redor. Uma baixa difusividade fará que um grande volume seja aquecido pelo calor contido no cordão. E quanto maior este volume, mais tensões térmicas serão criadas no material (mas não com maior intensidade, necessariamente). Lembrando-se sempre que as tensões geradas são de origem térmica, por isto denominadas de tensão térmica, que podem se manifestar levando o material ao colapso ou deformação, ou ficarem armazenadas na forma de tensões residuais).

Finalmente, é importante lembrar que as tensões são geradas em todos os sentidos em que houver contração. E que a porção contraída de um dado material (DL) é proporcional ao comprimento inicial (Lo) e à variação da temperatura $(\Delta \mathrm{T})$, representado de forma simplista por $\mathrm{DL}=\mathrm{Lo} \times \alpha \times \Delta \mathrm{T}$, onde $\alpha$ é o coeficiente de dilatação linear do material. Assim, as maiores tensões térmicas são geradas no sentido longitudinal do cordão de solda (normalmente referenciado como $\sigma y)$. Mas haverá também geração de tensão térmicas no sentido transversal $(\sigma x)$ e no sentido da espessura $(\sigma z)$.

Tomando agora o Modelo de 3 Barras, amplamente divulgado através do Welding Handbook da American Welding Society [5, p. 221]. Esse modelo, cuja adaptação de sua representação é feita na Figura 3, é muito usado para estimar qualitativamente as tensões térmicas a serem geradas num material, na ausência de solicitação externa e em que o sistema está em auto-equilíbrio (as barras inicialmente encontram-se à temperatura ambiente). Vamos considerar que as barras " $\mathrm{A}$ " $\mathrm{e}$ "C" estejam solidariamente engastadas nas barras " $\mathrm{D}$ " (barras estas rígidas, ou seja, podem se mover, mas não fletem ou se deformam plasticamente) e que a região central da barra "A" possa ser aquecida (recebendo calor de uma fonte externa), sem difundir calor mesmo para o restante da barra "A". Ao se aquecer por igual o centro da barra "A", ela tentará a se dilatar. Ao aquecer progressivamente, esta tendência à dilatação faria com que a barra " $A$ " empurrasse as barras " $D$ ", que por ser rígida puxariam as barras " $C$ ". Pensando no equilíbrio de ação e reação, a barra " $D$ ” estaria, por sua vez, comprimindo a barra "A". Assim, as barras "C" ficariam sob ação de tração, enquanto a barra "A" ficaria sob ação de compressão.

Entretanto, a região central da barra "A" ao ser continuamente aquecida passa a ter seu limite de escoamento reduzido na mesma proporção (a força aplicada faz apenas o material deformar, sem aumentar sua força de reação). Assim, a força exercida sobre a barra "D" devido à dilatação vai progressivamente se tornando menor. Supondo que a parte central da barra "A" alcance a temperatura de fusão, esta dilatação se torna nula (o liquido dilatando é compressível, além de compensar o crescimento pelas laterais sem resistência), assim como os esforços de tração sobre as barras "C" e o de compressão sobre a barra "A".

Mas, durante o resfriamento, a região da barra "A", após a solidificação, vai progressivamente tendo seu limite de escoamento aumentado. E a contração que agora toma lugar nesta região passa a puxar as barras "D", que, por sua vez, passam a comprimir as barras "C". Assim, ao completar o resfriamento, as barras " $\mathrm{C}$ " ficam sob a ação de compressão, enquanto a barra “A”, pelo efeito da ação-reação, fica sob ação de tração.

\section{O Modelo de 5 Barras para tensões geradas no sentido longitudinal ao cordão de solda}

Tomando-se agora o Modelo de 5 Barras proposto pelo autor 


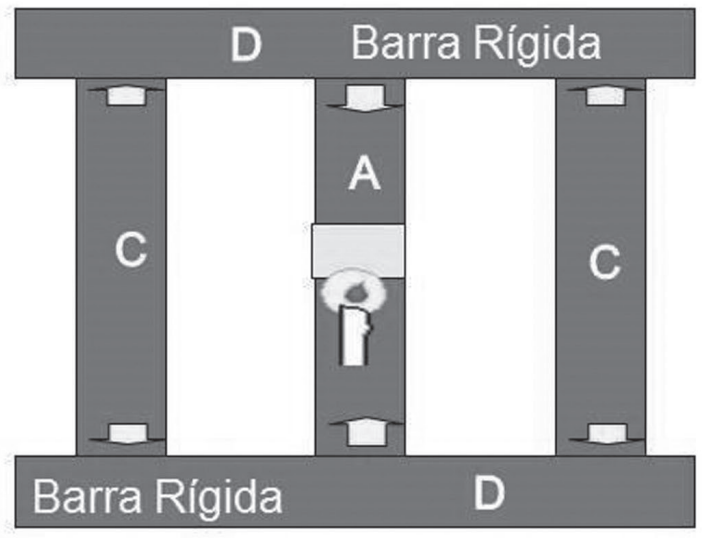

(a)

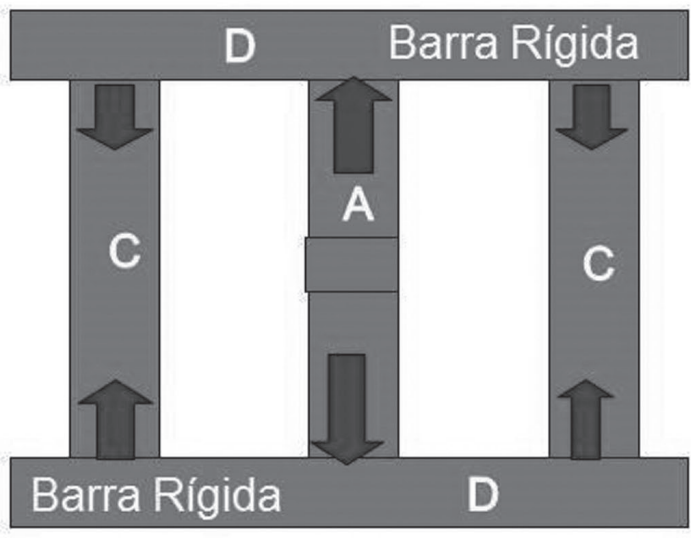

(b)

Figura 3. Modelo de 3 Barras para explicar a formação da geração de tensões térmicas no sentido longitudinal de uma solda (tradicional na literatura): em (a) durante o aquecimento (com fusão no centro da chapa "A"), enquanto em (b) após o resfriamento

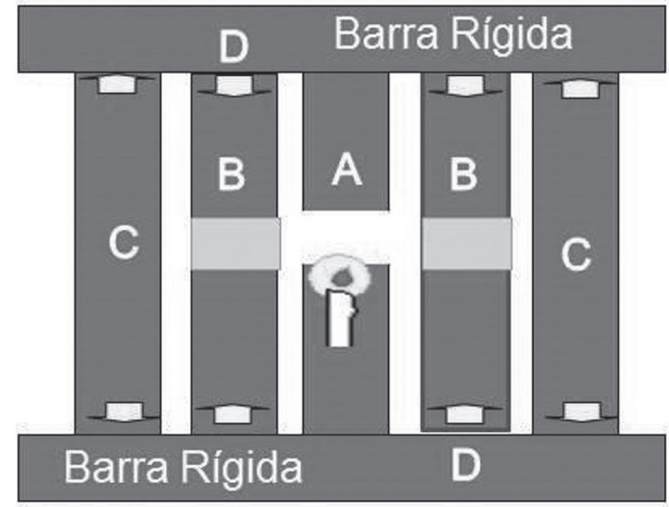

(a)

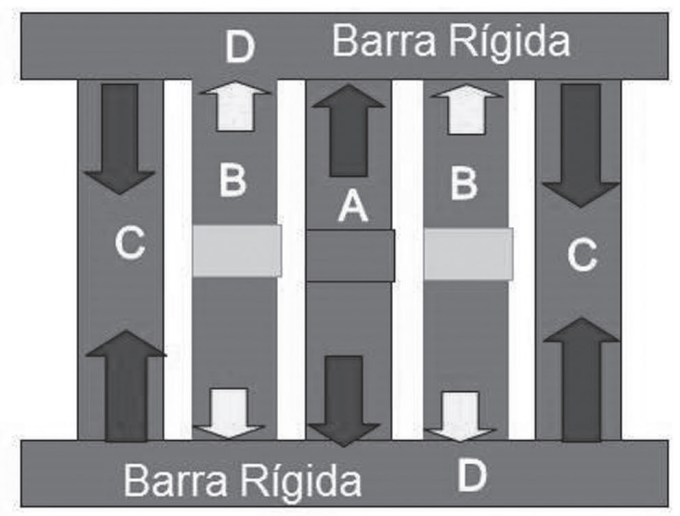

(b)

Figura 4. Modelo de 5 Barras para explicar a formação da geração de tensões térmicas no sentido longitudinal de uma solda: em

(a) durante o aquecimento (com fusão no centro da chapa “A” e não fusão no centro das chapas "B”), enquanto em (b) após o resfriamento

deste trabalho (Figura 4). No Modelo de 5 Barras, entre as barras "A" e "C" são colocadas duas outras barras, referenciadas como barras "B". Estas barras são também similarmente aquecidas no seu centro, como o centro da barra "A", mas recebendo menos calor. Esta condição equivale a uma região anexa à da barra " $\mathrm{A}$ ", aquecida por ela devido à difusão de calor. Assim, vamos supor que os centros das barras "B" alcancem ao final do aquecimento uma temperatura intermediária entre a parte central da barra "A" (temperatura de fusão) e a temperatura ambiente das barras "C". Assim, ao final do aquecimento, enquanto a barra "A" está sem ação de forças (seu centro está liquido), as barras "B” estão empurrando as barras " $D$ " (mesmo que com baixa força, já que o limite de escoamento na região central das barras " $\mathrm{B}$ " tornase menor devido ao aquecimento alcançado), que por sua vez estão puxando as barras "C". Ou seja, após o aquecimento, a barra " $A$ " não estará sob ação de qualquer força, as barras " $B$ " estarão sob a ação de uma pequena força de compressão (igual a do limite de escoamento do material da região central das barras "B") e as barras "C" ficarão sob a ação de tração, com o mesmo módulo de força aplicada sobre as barras B.

Já durante o resfriamento, tanto a barra "A" quanto as barras "B" começam a se contrair e puxar as barras "D". Mas, neste caso, ao mesmo tempo em que as barras "B" puxam as barras " $D$ ", elas são comprimidas pelas próprias barras " $D$ ", que estão sendo puxadas com maior força pela barra "A" (maior variação de temperatura, maior contração). Por analogia ao que acontece no Modelo de 3 Barras, ao final do resfriamento, tanto a barra "A" como as barras "B" ficarão sob a ação de tração, enquanto as barras "C" vão ficar sob ação de esforços de compressão. Entretanto, o valor da força de tração na barra central vai ser maior, enquanto as forças agindo sobre as barras " $B$ " têm suas forças finais calculadas pela diferença entre as forças de compressão impostas pela barra $\mathrm{A}$ e as forças de tração reativa resultantes das próprias barras " $\mathrm{B}$ ". $\mathrm{O}$ esforço compressivo resultante sobre as barras " $\mathrm{C}$ " será proporcional à intensidade $\mathrm{e}$ distribuição dos esforços trativos impostos sobre as barras " $D$ " pelas barras "A" e "B", como sugere a Figura 5. 


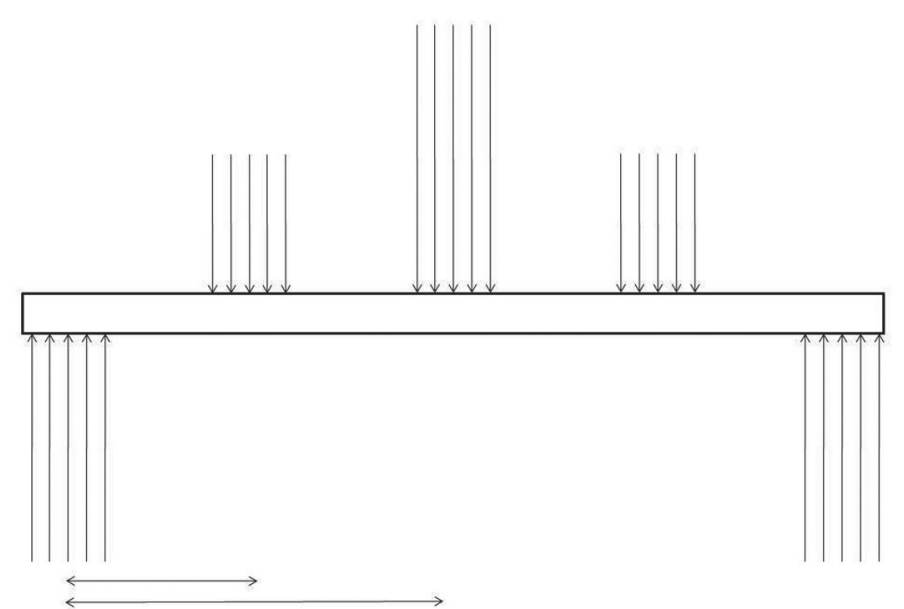

Figura 5. Esquema de determinação de forças de reação em função da posição e distribuição das forças aplicadas (a solução é o equilíbrio entre as forças aplicadas, sendo que as setas na horizontal representam escala de comparação entre as forças)

A forma de interligar o Modelo de 5 Barras a uma união soldada é a de considerar a barra "A" como a Zona Fundida (ZF), as barras "B" como as Zonas Afetadas pelo Calor (ZAC) e as barras "C" como metal de base (MB) não aquecido. Entre estes três elementos há uma continuidade, não havendo transições bruscas entre eles, como sugere a Figura 6, em que eles estão representados paralelamente num seção transversal da junta. Desta forma, o ponto de tensão zero (transição de tração para compressão) seria aquele em que o metal não mudou de temperatura devido ao processo de soldagem (na verdade, pode ter aquecido, mas não o suficiente para que a força atuante chegasse ao limite de escoamento do material naquela região, já que caso o material fique apenas no regime elástico, não se criariam tensões no resfriamento). Assim, a amplitude e a largura da atuação dos esforços e o ponto de inversão da região trativa-compressiva dependem do limite de escoamento do

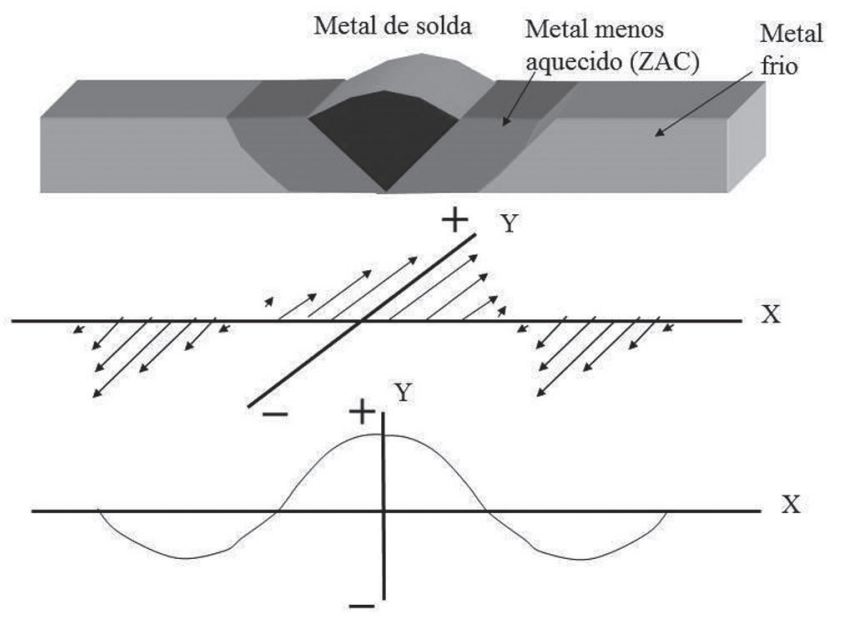

Figura 6. Representação das tensões térmicas geradas no sentido longitudinal de um cordão soldado(.) material (que varia entre $\mathrm{ZF}$ e ZAC e mesmo dentro da ZAC), da energia de soldagem (quanto maior, mais larga a ZAC) e da capacidade de difusão de calor do material (que quanto maior, mais estreita é a ZAC). Mas mesmo estas regras simples devem ser vistas com ressalvas. Por exemplo, Okano et al. [6] demonstraram e justificaram que distorção angular nem sempre é controlada pela convencional energia de soldagem (dada, para o caso das soldagens a arco elétrico, pela razão do produto da corrente-tensão e velocidade de soldagem). De acordo com eles, diferentes velocidades de soldagem para uma mesma energia de soldagem não reflete o mesmo grau de distorção.

Uma vez entendido como as tensões térmicas são geradas, deve-se entender qual valor ela alcança. Como se pode notar na Figura 7, a parte de cima do diagrama representa o aquecimento. Vai-se criando uma tensão de compressão sobre o material até que se atinja o seu limite de escoamento (linha O-P), que por sua vez torna-se menor em módulo com o aumento da temperatura (linha $\sigma$ esc). Assim, mesmo o material tentando se dilatar com o aumento de temperatura, a força de compressão sobre ele se reduz, devido a sua deformação plástica (ou seja, o esforço compressivo toma o valor do limite de escoamento, linha P-Q). No ponto Q o material torna-se líquido, fazendo com que a reação (consequentemente os esforços) seja nula. A parte de baixo do diagrama mostra o que ocorre durante o resfriamento. De forma similar, o material ao se solidificar passa a sofrer esforços de tração, crescente até que se atinja o seu limite de escoamento (linha $\mathrm{T}_{\text {fusao }}-\mathrm{R}$ ). Como o limite de escoamento volta a crescer com a redução da temperatura, também cresce o esforço trativo agindo sobre o material. Na temperatura ambiente, se estabelece o valor final da tensão térmica, que é igual ao valor do limite de escoamento (ponto S).

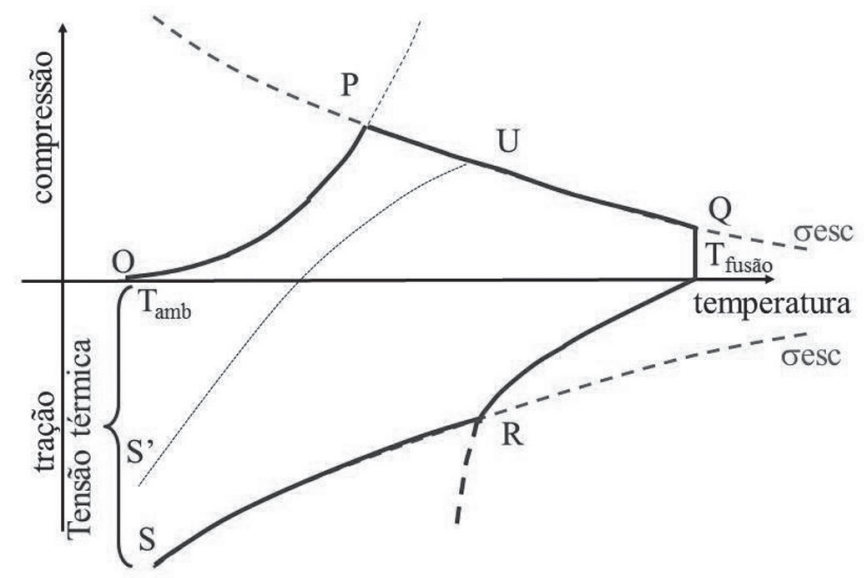

Figura 7. Diagrama ilustrativo da determinação da intensidade da tensão térmica gerada por um cordão de soldagem

$\mathrm{O}$ valor da tensão térmica pode até se tornar menor do que o limite de escoamento (ponto $S$ '), como no caso de uma parte do material que se aqueceu apenas até o ponto U. Mas o máximo que vai atingir será o valor da tensão do limite de escoamento. A região do material que se aqueceu apenas entre o ponto $\mathrm{O}$ e $\mathrm{P}$ não ficará sob tensão ao esfriar, pois a carga tanto no aquecimento (carregamento) quanto no resfriamento 

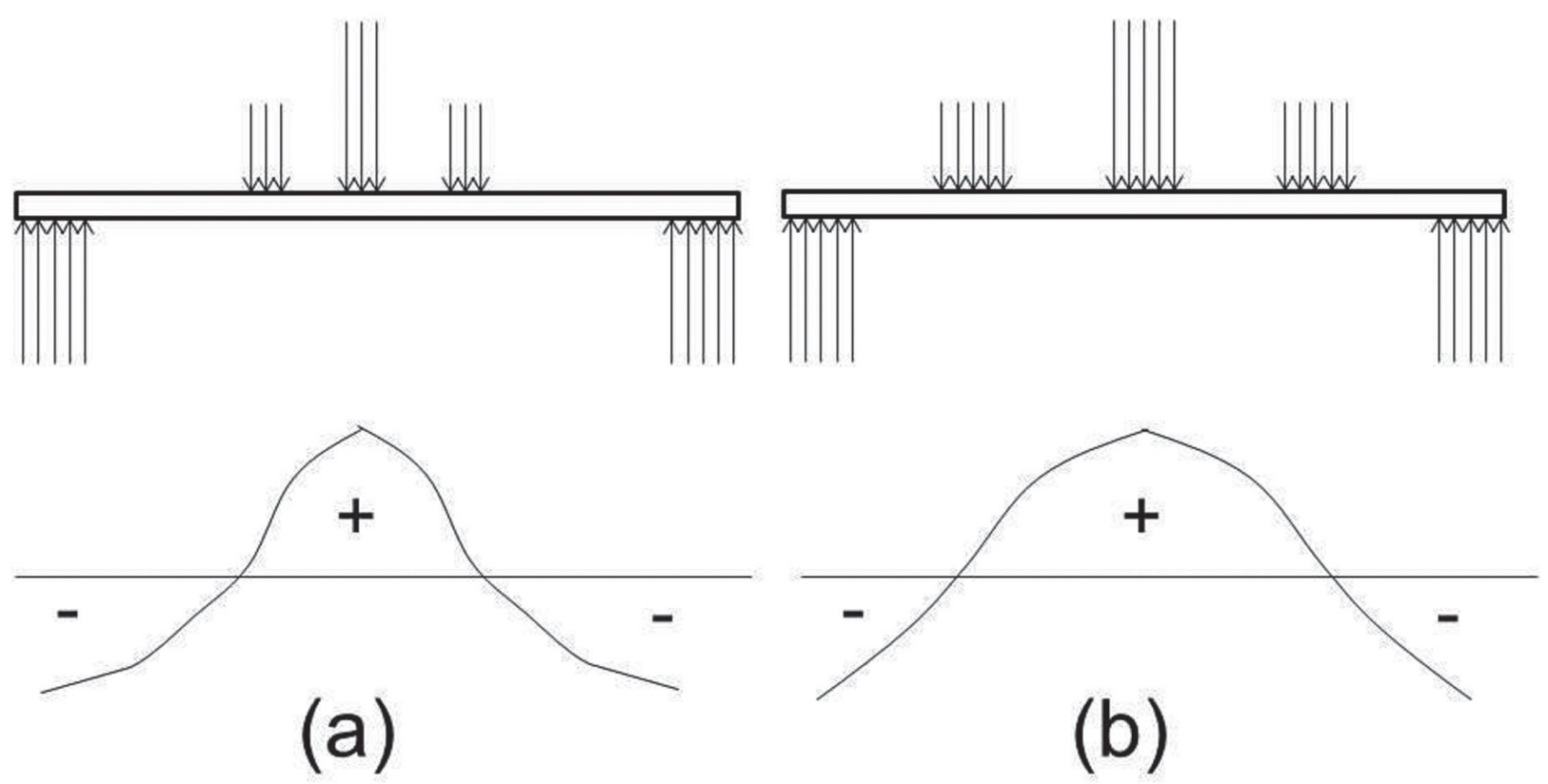

Figura 8. Esquema de distribuição de forças geradas por efeito térmico no material, comparando a condição de menor energia de soldagem (a) e maior energia (b) (.)

(descarregamento) segue a linha OP ou PO, respectivamente.

Entretanto, numa soldagem, cada região da ZF e da ZAC pode se comportar de forma diferente, ou seja, ter limites de escoamento diferentes. Isto acontece independentemente se a soldagem é com ou sem material de adição. $O$ valor da tensão térmica final vai ser no máximo o valor mais alto de limite de escoamento de todo sistema, mas sempre decrescente do centro para fora. É importante mencionar que uma vez atingido este valor máximo, pode acontecer do mesmo ser superior ao limite de escoamento de uma outra região do material, provocando sua deformação plástica localmente (acomodação) e reduzindo o valor máximo da tensão térmica resultante (tensão residual). O caso extremo de acomodação das tensões é a distorção, que faz aliviar as tensões térmicas geradas pela deformação plástica macroscópica do material.

\section{Aplicações do Modelo de 5 Barras para explicar situações práticas em soldagem}

Em soldagem, uma maior energia de soldagem provoca mais tensões térmicas (deformações e/ou tensões residuais). Uma maior energia de soldagem vai em geral fazer crescer o volume do material aquecido, provocando mais contração. Esta forma de pensar está em concordância com Bachorski et al. [4], para quem a contração térmica linear de um volume é a força motriz para distorção (eles propõem um modelo quantitativo para prever distorções baseado no volume do cordão, sem a necessidade de determinar gradientes de temperatura e mudanças microestruturais). De forma similar, uma ampliação de volume seria como aumentar as larguras das barras " $\mathrm{A}$ " $\mathrm{e}$ "B" do Modelo de 5 Barras (Figura 4), com consequências sobre a distribuição de forças esquematizadas pela Figura 5, como ilustra a Figura 8. Notar que a intensidade das forças seria a mesma independentemente da energia, pois a mesma depende do limite de escoamento do material, mas a largura da faixa em que as tensões são geradas é maior. Ou seja, um maior volume do material ficará sob ação de tensões térmicas.

Além da energia de soldagem em si, a concentração da energia também se torna um parâmetro de grande importância na geração de tensões térmicas. Quanto mais concentrado, mais se aquece a região antes do calor se dissipar. O Laser é um processo que produz alta concentração de energia na forma de calor, enquanto a soldagem a gás oxi-combustível age de forma oposta; na soldagem a gás há grande deformação, pois, como o calor não é concentrado, ao mesmo tempo que é cedido para a peça ele se dissipa pela própria peça, aquecendo um grande volume da mesma.

O Modelo de 5 Barras também pode ser aplicado para entender o efeito do pré-aquecimento sobre a geração de tensões térmicas. Existe a crença geral de que a prática de préaquecimento da chapa diminui a geração de tensões térmicas. Isto só seria verdade caso este pré-aquecimento abrangesse todo o volume da peça a ser soldada (que não é a prática em soldagem), de tal forma que a diferença de temperaturas $(\Delta \mathrm{T})$ entre as regiões da peça fosse menor e, assim, menos contração, além da necessidade de se garantir que o resfriamento da temperatura de pré-aquecimento até a temperatura ambiente se desse por igual em toda a peça (barras "A", "B" e "C" se tornam iguais). Efeito similar se consegue com pré-aquecimento quando a peça é pequena, pois após a solda a temperatura se homogeneíza (difusão do calor dentro da chapa é limitado pelas bordas), com resfriamento quase que homogêneo. Na verdade, pelo modelo proposto e em caso em que o pré-aquecimento é localizado, o pré-aquecimento faria com que mais calor fosse colocado na chapa, aumentando o volume do material que sofrerá contração (como se fosse alargada as barras "B" da figura 4). Em módulo, as 
tensões na barra "B" seriam as mesmas, mas elas seriam geradas numa maior porção do material. Então, pré-aquecimento por si só não reduz a geração de tensões. O conceito inverso do préaquecimento é o do resfriamento da chapa logo após soldagem (técnica denominada "trailing heat sink" por Yang \& Dong [7], que mostra sua aplicabilidade). Ishizaki et al. [8], usando gelo seco, demonstraram a redução das tensões térmicas ao resfriar uma solda TIG sobre aço inoxidável, à temperatura ambiente e pré-aquecido a $200{ }^{\circ} \mathrm{C}$. Eles concluiu que quanto maior o gradiente de temperatura, maior é a redução da tensão residual, o que confirma o raciocínio acima de que pré-aquecimento (menor gradiente) não favorece o alívio de tensões.

Por outro lado, a menor velocidade de resfriamento conseguida com o pré-aquecimento pode fazer com que microestruturas mais favoráveis sejam obtidas na ZAC e ZF, abaixando o limite de escoamento do material naquelas regiões. Assim, as tensões térmicas seriam de menor intensidade, mas de forma indireta. Bezerra et al. [9] modelaram o efeito do pré-aquecimento sobre a geração de tensão térmica com o material de base apresentando condições de resistência mecânicas diferenciadas na região da ZAC, a saber, desde amolecido pelo ciclo térmico, passando por inalterado, até endurecido pelo ciclo térmico. Observaram uma diminuição contínua da tensão térmica de tração longitudinal máxima (na linha central do cordão de solda) com o aumento da temperatura de preaquecimento. Contudo, ocorreu uma elevação significativa das tensões na região sob tração (onde ocorre propagação de trincas). Eles concluíram, então, que o preaquecimento é indesejável do ponto de vista de geração de tensões residuais (maior o pré-aquecimento, maior a zona de tensões trativas), sendo mais característico em materiais que não amolecem com o preaquecimento.

Desta forma, o efeito do pré-aquecimento vai depender da composição química do material a ser soldado e da energia de soldagem já imposta. Por isto, este autor recomenda como boa prática usar menor energia de soldagem com pré-aquecimento para evitar microconstituintes frágeis, normalmente com alto limite de escoamento, ao invés de alta energia de soldagem. Existe ainda o caso em que o pré-aquecimento seja feito em temperaturas tão altas que se consiga transformar um material de baixa em alta ductilidade (como no caso dos ferros fundidos). Neste último caso é imprescindível que tanto o aquecimento quanto o resfriamento se deem com uma taxa bem homogênea em toda a peça, pois a própria contração diferenciada ao longo das espessuras (devido a maior temperatura no centro ou na superfície) poderá causar tensões térmicas significantes.

Uma técnica muito comum aplicada em soldagem de aços susceptíveis à fragilização da ZAC grosseira é o uso de amanteigamento da superfície da junta, ou mesmo o próprio preenchimento da junta (como em soldagens de ferros fundidos "a frio"), com eletrodos de níquel. O níquel possui baixo limite de escoamento e alta deformabilidade (permitindo que não se aumente significativamente o seu limite de escoamento com pequenas deformações causadas pelas tensões térmicas). Desta forma, de acordo com o Modelo de 5 Barras, quando as tensões térmicas são geradas pela contração do material da ZF e da ZAC, elas são limitadas pela camada de Ni (acomodação das tensões), fazendo com que a tensão térmica final seja de baixo valor.

\section{O Modelo de 1 Barra para tensões geradas no sentido transversal ao cordão de solda}

As tensões térmicas geradas no sentido transversal ao cordão de solda são as responsáveis pelo, por exemplo, "embicamento" (empenamento angular) da junta soldada, como ilustra a Figura 9. Isto acontece quando há variação de volume ao longo da espessura da chapa, fazendo com que maior contração, consequentemente tensões térmicas de maior intensidades, se deem na região mais volumosa. Caso o cordão fosse de igual dimensão em toda a espessura, não haveria empenamentos, mas sim tensões que poderiam se armazenar como tensões residuais. Mas diferentemente do sentido longitudinal, pode haver ou não restrição ao movimento da peça. Caso não haja restrições ao movimento transversal (externa ou internamente, a última chamada de autorestrição, devido à espessura da chapa), a chapa acompanha a contração e não se gera tensões ao final. Quando houver restrições ao movimento transversal e/ou angular, aparecerão as tensões térmicas permanentes (tensões residuais).

O Modelo de 1 Barra apresentado na Figura 10 se diferencia dos Modelos de 3 e 5 Barras, aplicáveis para tensões térmicas geradas no sentido longitudinal ao do cordão, devido às restrições. No sentido longitudinal, sempre vai haver um região da chapa (paralelamente ao longo do cordão, representada pelas barras "C" nos citados modelos) que contrabalança os esforços da dilatação e contração da zona fundida. Por isto, nessa região se criam tensões compressivas, de igual módulo às tensões trativas das regiões que se contraem durante o resfriamento

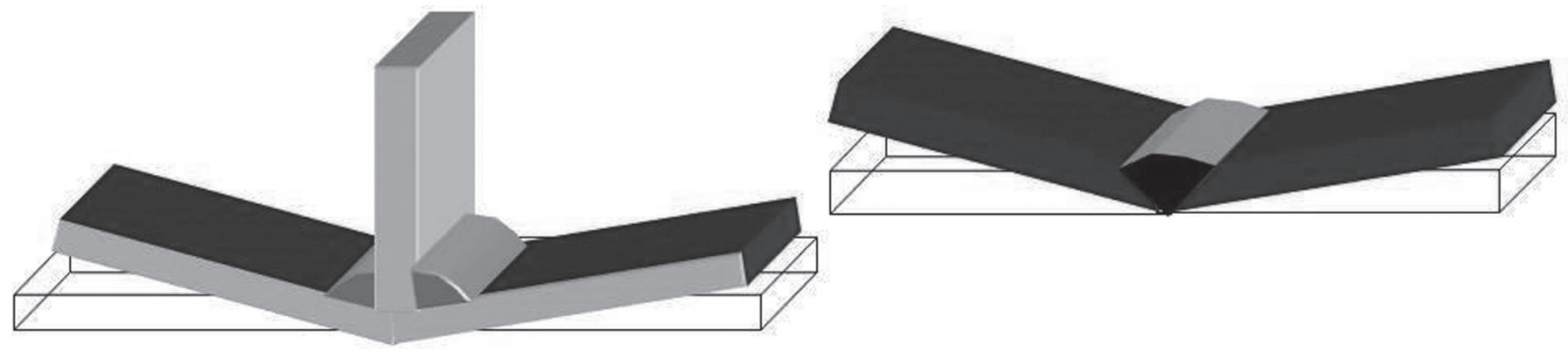

Figura 9. Empenamento angular de chapas devido a tensões térmicas no sentido transversal ao cordão de solda de forma desigual ao longo da espessura da chapa e ao fato de não haver restrição ao movimento angular pelas chapas 


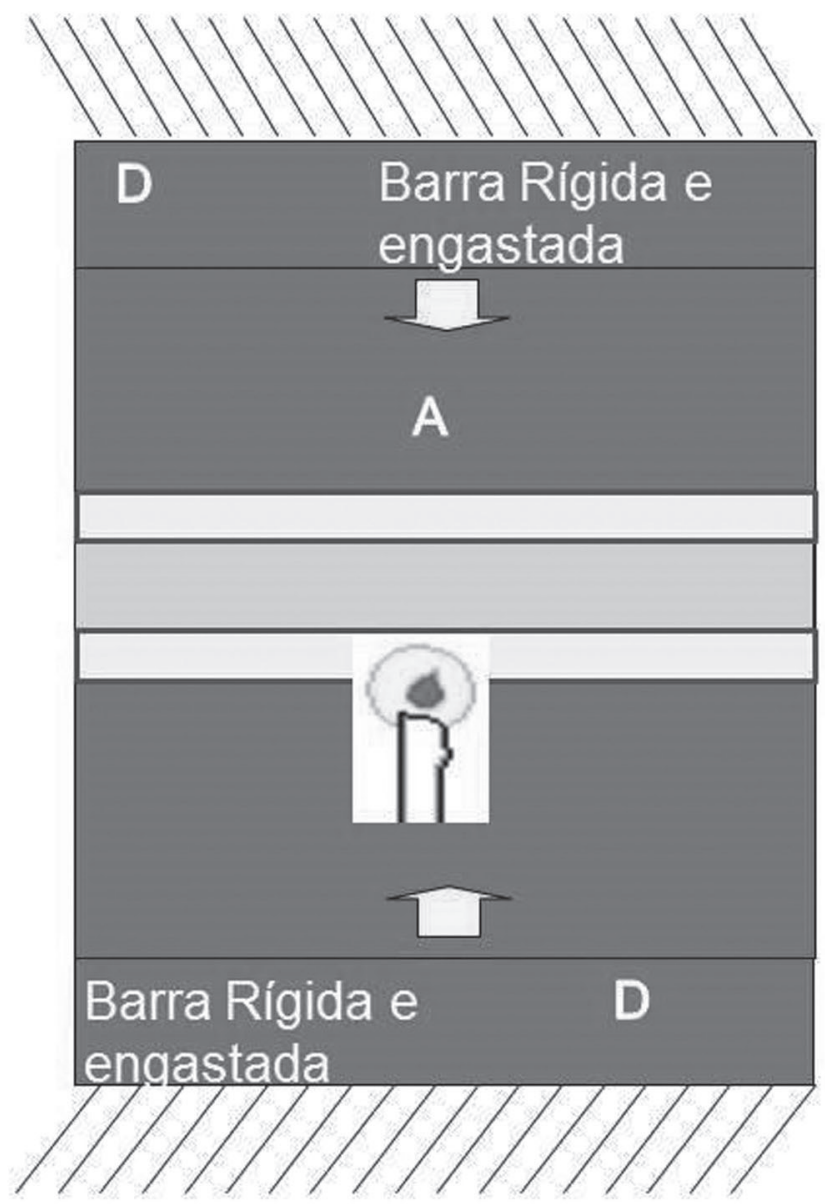

(a)

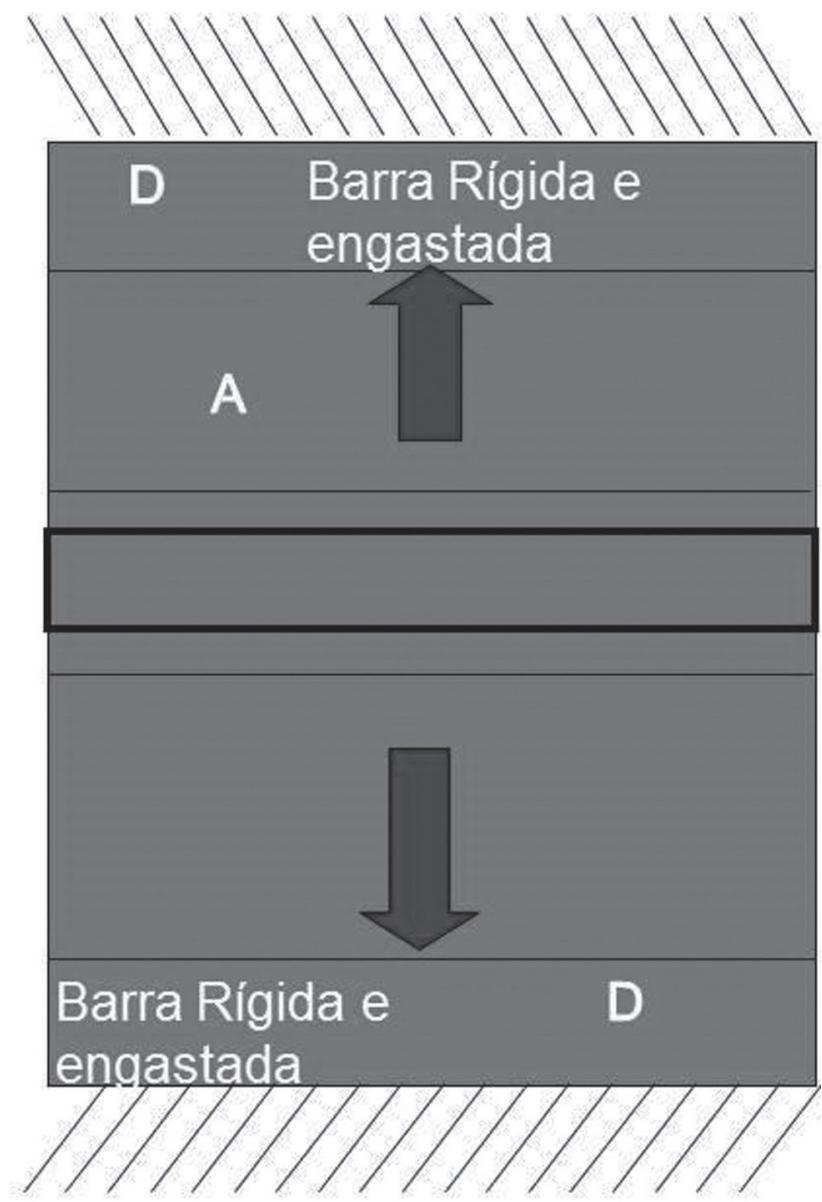

(b)

Figura 10. Modelo de 1 Barra para explicar a formação da geração de tensões térmicas no sentido transversal de uma solda: em (a) durante o aquecimento (com fusão no centro da chapa "A" e aquecimento decrescente na vizinhança do centro), enquanto em (b) após o resfriamento

(representadas pelas letras "A" e "B" nos modelos). Já no sentido transversal, ao longo de toda a seção da chapa onde houver a deposição de um cordão haverá a contração durante o resfriamento. Então, caso não haja restrição ao movimento e haja a possibilidade da chapa fletir ou deformar plasticamente (o que não acontece em placas rígidas), não haveria geração de tensões. Somente quando há restrição (chapa engastada) e comportamento rígido da região não aquecida da placa da solda que se configurarão as condições para haver tensões transversais térmicas.

Vamos considerar que a barra "A" esteja solidaria ao longo das barras "D" (barras estas rígidas e engastadas, ou seja, não podem se mover, nem fletir ou deformar plasticamente) e que a região central da barra "A" possa ser aquecida (recebendo calor de uma fonte externa), difundindo calor para sua vizinhança, mas não ao restante da barra "A". Ao se aquecer o centro da barra "A", ela tentará a se dilatar. Progressivamente se aquecendo, esta tendência à dilatação faria com que a barra " $\mathrm{A}$ " empurrasse as barras " $\mathrm{D}$ ", que por serem rígidas e engastadas comprimiriam a barra "A". Assim, a barra "A" ficaria sob ação de compressão.
Analogamente ao caso da análise da geração de tensões longitudinais, a região central da barra " $A$ " ao ser continuamente aquecida passa a ter seu limite de escoamento progressivamente reduzido (a força aplicada faz apenas o material se deformar, sem aumentar sua força de reação). Assim, a força exercida sobre a barra "D" devido à dilatação vai paulatinamente se tornando menor. Quando a parte central da barra "A" alcança a temperatura de fusão, esta dilatação se torna nula (o liquido dilatando é compressível, além de compensar o crescimento pelas laterais sem resistência), independentemente da dilatação da região vizinha à sua região central. Assim, também se tornam nulos os esforços sobre a barra "A". Mas, durante o resfriamento, a região central (e vizinhança) da barra "A”, após a solidificação, vai progressivamente tendo seu limite de escoamento aumentado. E a contração que agora toma lugar nessa região passa a puxar as barras " $D$ ", que, por sua vez, tracionam a barra "A".

Desta forma, no sentido transversal, quando há restrição ao movimento e não há deformação plástica do material, não há tensões compressivas, tão somente trativas, com intensidades iguais a do limite de escoamento da região com maior resistência. 


\section{Conclusões}

O Modelo de 5 Barras proposto demonstrou descrever melhor o fenômeno de geração de tensões térmicas longitudinalmente ao cordão de solda do que o popular Modelo de 3 Barras, por permitir explicar o comportamento das tensões geradas com a existência de uma região entre a Zona Fundida (ZF) e o metal de base (MB), ou seja, com a presença da Zona Afetada pelo Calor (ZAC). Fica mais fácil entender descritivamente, e sem necessidade de cálculos avançados, a razão para que as tensões na ZAC sejam progressivamente menores do que na $Z F$, se anulando numa distância transversal da ZF em que as tensões térmicas atuantes não tenham alcançado o limite de escoamento da região do material (portanto, um pouco afastado da linha inferior da ZAC, e não nessa linha, como muitas vezes ilustrado nos trabalhos técnicos e científicos). Também mostrou ser capaz de explicar que as maiores tensões vão ser geradas na ZF e que as tensões finais na junta serão definidas pelas propriedades mecânicas (limite de escoamento) do material do cordão. Mas que pode se ter na ZAC tensões tão altas como as do MF, desde que o material da ZAC grosseira possua limite de escoamento mais alto do que do material da ZF, passando a definir o valor da tensão térmica final gerada.

Já o Modelo de 1 Barra mostrou ser capaz de explicar que quando não se tem restrições ao movimento ou deformação plástica do material, as tensões térmicas criadas no sentido transversal ao cordão de solda são sempre trativas, cujos módulos dependem também do limite de escoamento da região mais resistente do material.

\section{Referências Bibliográficas}

[1] PEARCE, S.V.; LINTON, V.M.; OLIVER, E.C.; Residual stress in a thick section high strength T-butt weld,

[2] PARANHOS, R.P.R; FRADE, P.R.; GUIMARÃES, A.S.; PAYÃO, J., Efeito da Adição de Ti na Resistência a Tração do Metal de Solda C-Mn após Tratamento Térmico de Alívio de Tensões, Soldagem Insp., 6 (3) [Jul/Set] 2002, pp.20-24

[3] YANG, Y.P.; Understanding of Vibration Stress Relief with Computation Modeling, Journal of Materials Engineering and Performance, 18(7), Oct 2009, pp. 856-862, DOI: 10.1007/ s11665-008-9310-9

[4] BACHORSKI, A.; PAINTER, M.J.; SMAILES, A.J.; WAHAB, M.A., Finite-element prediction of distortion during gas metal arc welding using the shrinkage volume approach, Journal of Materials Processing Technology, 1999, 92-93, pp. 405-409

[5] AWS, Welding Handbook - Vol 1: Welding Technology, Chapter 7: residual Stresses and Distortion, American Welding Society, $8^{\circ}$ Edition, 891 p., ISBN: 0-87171-281-4

[6] OKANO, S.; MATSUSHITA, K.; MOCHIZUKI, M.; TOYODA, M., A discussion of the relationship between heat input parameter and angular distortion by considering moving heat source effect, Welding International, 2012, doi:10.1080/09 507116.2012.753239

[7] YANG, Y.P. \& DONG, P., Buckling Distortions and Mitigation Techniques for Thin-Section Structures, Journal of Materials Engineering and Performance, 21(2), feb 2012, pp.153-160, DOI: 10.1007/s11665-011-9928-X

[8] ISHIZAKI, Y.; ASAI, S.; TANABE, T.; YASUDA, Y.; TAKEBAYASHI, H., Development of GTAW system using CO2 cooling for reducing residual stress, IIW doc XII-1941-08 Materials Science and Engineering A, 480 (2008), pp. 411-418, doi:10.1016/j.msea.2007.07.032

[9] BEZERRA, A.C., RADE, D.A. \& SCOTTI, A., Efeito do Preaquecimento sobre as Tensões Residuais de Soldagem, Soldagem \& Inspeção 11 (1), jan/mar 2006, pp.54-61 (ISSN 0104-9224) 